\title{
BUCKLING STABILITY ASSESSMENT OF PLATES UNDER UNIAXIAL COMPRESSION
}

\author{
Farhad Riahi' ${ }^{1}$, Tadeh Zirakian², Vahed Mam Ghaderi' ${ }^{1}$, Souran Arya ${ }^{1}$ \\ 1 Department of Civil Engineering, Mahabad Branch, Islamic Azad University, Mahabad, Iran \\ 2 Department of Civil Engineering and Construction Management, California State University, Northridge, CA, \\ USA, e-mail: tadeh.zirakian@csun.edu
}

Received: 2018.03 .15

Accepted: 2018.05.01

Published: 2018.06.01

\begin{abstract}
Buckling of thin-walled and load-bearing elements of a structure can have devastating consequences. Hence, buckling checks are an integral part of strength analysis of structures. The buckling problem of thin rectangular plates subjected to in-plane compressive and/or shear loading is of great importance in building, bridge, aerospace, marine, and shipbuilding industries. When buckling occurs, thin plates undergo large out-of-plane deflections, which in turn results in the development of large bending stresses and eventually complete failure of the structure. This paper deals with the buckling stability assessment of uniaxially-compressed plates with different support conditions within the framework of classical plate theory. The main objective of this research is to explore some uncovered aspects of buckling stability of plates by considering the effects of support conditions, aspect ratio, and slenderness ratio, which will consequently result in efficient design of such thin-walled structures. To this end, in addition to validation of the numerical simulation, some case studies have been performed in order to gain a better understanding of different aspects of buckling stability of such thin-walled structures.
\end{abstract}

Keywords: Plates, Buckling, Support conditions, Aspect ratio, Design Ratio, Slenderness ratio, Numerical simulation.

\section{INTRODUCTION}

Thin-walled structures are widely used in various engineering industries, which seek efficiency in strength and cost by minimizing material. They include industrial and residential buildings, bridges, ship hulls, aircraft skins, tanks, pipes, culverts, and the like. Thin plates usually have slenderness ratios between 10 and 100 and are often subjected by normal compressive and/ or shearing (in-plane) loads acting in the middle plane of the plate. Slender plates undergo elastic buckling and then yield in the post-buckling stage. Considering the widespread applications of thin-plated structures, accurate prediction of their buckling capacity is of great importance in efficient analysis and design of such structures. The buckling capacity of a plate is a function of its geometrical (slenderness) and material properties (Navier, 1823; Ventsel and Krauthammer, 2001).

The buckling problem for a simply supported plate subjected to direct, constant compressive forces acting in one and two directions was first solved by Bryan (1890) using the energy method. Dinnik (1911) completed the buckling problem for circular compressed plates. The effect of the direct shear forces on the buckling of a rectangular simply supported plate was first studied by Southwell and Skan (1924). Cox (1933) presented solutions of various buckling problems for thin rectangular plates in compression. A comprehensive analysis of linear and nonlinear buckling problems for thin plates with various shapes under different types of loads as well as a considerable presentation of 
available results for critical forces and buckling modes, which can be used in engineering design, was provided by Gerard and Becker (1957), Timoshenko and Gere (1961), and Cox (1963). Later on, Najafizadeh et al. (2010) studied the buckling of simply supported rectangular plates under nonuniformly distributed in-plane compressive loadings by utilizing Galerkin method.

Latifi et al. (2013) reported a study on the buckling problem of thin rectangular functionally graded plates subjected to proportional biaxial compressive loadings with arbitrary edge supports. The buckling analysis was carried out using Fourier expansion method and Stokes' transformation. The validity and accuracy of this approach in the buckling analysis of thin rectangular FGM (functionally graded material) plates were shown and the effects of the plate aspect ratio, FGM power index, and loading proportionality factor on the buckling capacity of an FGM plate were investigated. Mijušković et al. (2014) presented an accurate buckling analysis for thin rectangular plates under locally distributed compressive stresses, where the accurate results were obtained using the Ritz method together with the exact in-plane stress distributions. It was found that analytical procedures for the exact stress and displacement function determinations in forms of series are very complex, thus commercial softwares such as Mathematica or Maple have to be resorted for symbolic computations. In addition, studies reported by Wang et al. (2007) and Wang (2015) showed that the differential quadrature method can yield accurate buckling loads for rectangular plates under uniformly or non-uniformly distributed edge compressions.

Lately, Kilardj et al. (2016) investigated the linear and nonlinear buckling of a thin, simply supported, partially stretched, and non-defective plate through numerical simulation. It was shown that local tensile loading can induce buckling instability in thin plates with no defects. In another study, a finite element formulation based on two-variable refined plate theory was developed by Rouzegar and Sharifpoor (2017) for buckling analysis of isotropic and orthotropic plates. The accuracy of predictions of this method was shown and the effects of orthotropy ratio, side-to-thickness ratio, and different types of boundary conditions on the buckling loads were studied as well. Most recently, Rammerstorfer (2018) investigated the bifurcation buckling under tensile loading of beams, plates (with and without cut-outs), rolled metal strips, thin cell walls of foams, and of some nanometers thick metallic films on polymeric substrates. It was shown that in all cases of buckling under tensile loads eventually compressive stresses are responsible for the loss of stability.

In this paper, the effects of support conditions, aspect ratio, and slenderness ratio on the buckling stability of plates under uniformly-distributed compressive load are investigated. The accuracy of the current analysis is validated through comparison studies. Several case studies are then performed in order to gain a better understanding of some uncovered aspects of buckling stability of such thin-walled structures.

\section{CHARACTERISTICS OF PLATE MODELS}

In this research, detailed investigations are made on the buckling stability of rectangular plates with various support conditions, subjected to uniaxial compression through numerical simulation. Fig. 1 shows a typical rectangular plate under uniformly-distributed uniaxial compressive stresses. The details of the considered four different support conditions, i.e. SSSS, CSCS,

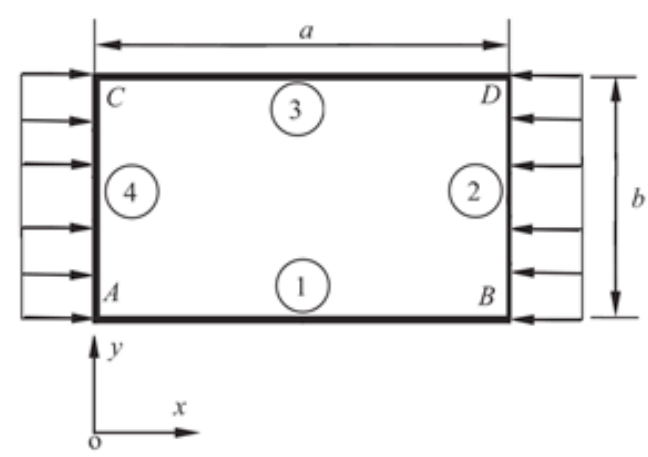

Fig. 1. Rectangular plate under uniaxial compressive stresses 
Table 1. Considered plate support conditions

\begin{tabular}{|c|c|c|c|c|}
\hline \multirow{2}{*}{ Plate edge in Fig. 1. } & \multicolumn{4}{|c|}{ Edge supports $^{\mathbf{a}}$} \\
\cline { 2 - 5 } & CCCC & CSCS & SCSC & SSSS \\
\hline $1(\mathrm{AB})$ & $\mathrm{C}$ & $\mathrm{C}$ & $\mathrm{S}$ & $\mathrm{S}$ \\
\hline $2(\mathrm{BD})$ & $\mathrm{C}$ & $\mathrm{S}$ & $\mathrm{C}$ & $\mathrm{S}$ \\
\hline $3(\mathrm{CD})$ & $\mathrm{C}$ & $\mathrm{C}$ & $\mathrm{S}$ & $\mathrm{S}$ \\
\hline $4(\mathrm{AC})$ & $\mathrm{C}$ & $\mathrm{S}$ & $\mathrm{C}$ & $\mathrm{S}$ \\
\hline
\end{tabular}

${ }^{a}$ C: Clamped support \& S: Simple support

Table 2. Geometrical properties of plate models with $6 \mathrm{~mm}$ thickness

\begin{tabular}{|c|c|c|c|c|c|c|c|c|c|c|c|c|c|c|}
\hline \multirow[b]{2}{*}{$\begin{array}{l}\text { Plate } \\
\text { model }\end{array}$} & \multicolumn{2}{|c|}{$\alpha=a / b=0.5$} & \multirow[b]{2}{*}{$\begin{array}{l}\text { Plate } \\
\text { model }\end{array}$} & \multicolumn{2}{|c|}{$a=a / b=1.0$} & \multirow[b]{2}{*}{$\begin{array}{l}\text { Plate } \\
\text { model }\end{array}$} & \multicolumn{2}{|c|}{$\alpha=a / b=1.5$} & \multirow[b]{2}{*}{$\begin{array}{l}\text { Plate } \\
\text { model }\end{array}$} & \multicolumn{2}{|c|}{$\alpha=a / b=2.0$} & \multirow[b]{2}{*}{$\begin{array}{l}\text { Plate } \\
\text { model }\end{array}$} & \multicolumn{2}{|c|}{$\alpha=a / b=2.5$} \\
\hline & $\begin{array}{c}\text { A } \\
(\mathrm{mm})\end{array}$ & $\begin{array}{c}\mathrm{b} \\
(\mathrm{mm})\end{array}$ & & $\begin{array}{c}\mathrm{a} \\
(\mathrm{mm})\end{array}$ & $\begin{array}{c}\mathrm{b} \\
(\mathrm{mm})\end{array}$ & & $\begin{array}{c}\mathrm{a} \\
(\mathrm{mm})\end{array}$ & $\begin{array}{c}\mathrm{b} \\
(\mathrm{mm})\end{array}$ & & $\begin{array}{c}\mathrm{a} \\
(\mathrm{mm})\end{array}$ & $\begin{array}{c}\mathrm{b} \\
(\mathrm{mm})\end{array}$ & & $\begin{array}{c}\mathrm{a} \\
(\mathrm{mm})\end{array}$ & $\begin{array}{c}\mathrm{b} \\
(\mathrm{mm})\end{array}$ \\
\hline $\mathrm{P}-1$ & 250 & 500 & $P-9$ & 250 & 250 & $P-1$ & 375 & 250 & $\mathrm{P}-25$ & 500 & 250 & P-33 & 625 & 250 \\
\hline P-2 & 500 & 1000 & 10 & 500 & 500 & $P$ & 750 & 50 & $\mathrm{P}-26$ & 10 & 500 & P-34 & 1250 & 500 \\
\hline P-3 & 750 & 1500 & P-11 & 750 & 50 & $P$ & 1125 & 750 & -27 & 1500 & 750 & P-35 & & 50 \\
\hline P-4 & 000 & 2000 & 12 & 100 & 1000 & P-2 & 150 & 100 & P-28 & 20 & 100 & D-3 & 25 & 1000 \\
\hline P-5 & 1250 & 2500 & P-13 & 1250 & 1250 & P-21 & 1875 & 1250 & P-29 & 2500 & 1250 & P-37 & 31 & 1250 \\
\hline P-6 & 1500 & 3000 & P-14 & 1500 & 1500 & P-22 & 2250 & 1500 & P-30 & 3000 & 1500 & P-38 & 3750 & 1500 \\
\hline P-7 & 1750 & 3500 & P-15 & 1750 & 1750 & $\mathrm{P}-23$ & 2625 & 1750 & $P-31$ & 3500 & 1750 & P-39 & 5 & 1750 \\
\hline P-8 & 2000 & 000 & $P-16$ & 2000 & 2000 & P-24 & 3000 & 2000 & P-32 & 4000 & 2000 & $\mathrm{P}-40$ & 5000 & 2000 \\
\hline
\end{tabular}

SCSC, and CCCC, are also provided in Fig. 1 and Table 1. As shown in Fig. 1, the lengths of the plate along $x$-axis and $y$-axis are denoted by $a$ and $b$, respectively. In addition, the plate possesses a uniform thickness $(t)$ along $z$-axis. It is also noted that the plate is subjected to uniformly-distributed compressive stresses $\left(P_{x}\right)$ along $x$-axis and the magnitude of the uniformly-distributed compressive stresses is $25 \mathrm{MPa}$.

$a$ varies between $250 \mathrm{~mm}$ and $5000 \mathrm{~mm}$ and $b$ varies between $250 \mathrm{~mm}$ and $4000 \mathrm{~mm}$. The thickness of the plate is considered to be constant and $6 \mathrm{~mm}$ in all cases. The geometrical properties of the considered plate models are summarized in Table 2. As seen in the table, different values of plate aspect ratio $\alpha=a / b$ ranging from 0.5 to 2.5 are considered. It should be noted that four different support conditions, i.e. SSSS, CSCS, SCSC, and $\mathrm{CCCC}$, are considered for each individual model tabulated in Table 2, i.e. P-1 through P-40, which results in a total of 160 plate models with different geometrical properties as well as support conditions.

Lastly, the plate models are assumed to be made of steel, having a Young's modulus of 210 $\mathrm{GPa}$, yield stress of $355 \mathrm{MPa}$, Poisson's ratio of 0.3 , tangent modulus of $2.1 \times 10^{5} \mathrm{MPa}$, and bulk density of $7850 \mathrm{~kg} / \mathrm{m}^{3}$.

\section{FINITE ELEMENT MODELING DETAILS}

Plates were modeled and analyzed using ABAQUS (2016) and PLATE-BUCKLING (2015) programs, in this study. ABAQUS (2016) is a commercial software suitable for finite element analysis and computer-aided engineering. PLATEBUCKLING (2015) is based on the finite element method and is used to perform plate buckling analysis for stiffened and unstiffened plates in accordance with EN 1993-1-5 and DIN 18800-3. Two typical finite element models of plates developed using ABAQUS (2016) and PLATE-BUCKLING (2015) programs are illustrated in Fig. 2.

In numerical simulation using ABAQUS (2016) software, plates were modeled using S8R5 element. This is an eight-node doubly-curved thin shell element with reduced integration points and five degrees of freedom, viz. three translational and two in-plane rotational, per node. The analysis started with a load-control standard NewtonRaphson iterative procedure in the initial stages of loading and then shifted to a modified Riks procedure as the ultimate load was approached.

In numerical simulation using PLATEBUCKLING (2015) program, plates were modeled using an eight-node surface element. The eigenvalues and corresponding buckling shapes of 

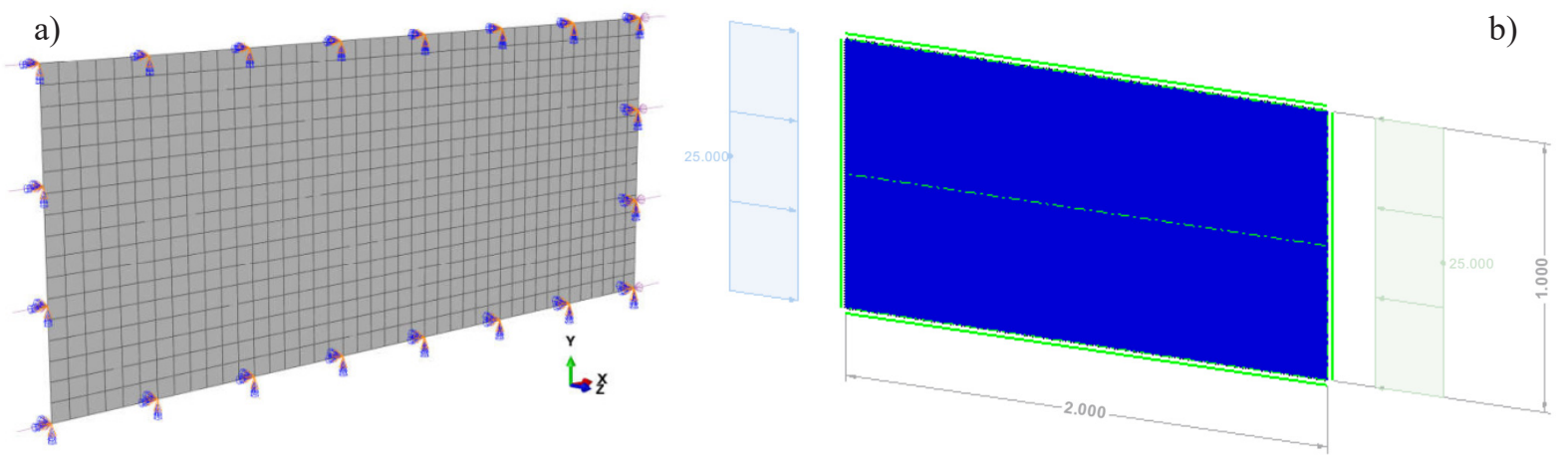

Fig. 2. Typical finite element models of plates, a) ABAQUS model, b) PLATE-BUCKLING model

plates were determined using the Lanczos method. The first buckling mode shapes for plates with different support conditions and aspect ratios are shown in Fig. 3.

\section{DISCUSSION OF RESULTS}

\section{Verification of Numerical Predictions}

The finite element results as well as findings of this study are presented and discussed in Section 4 . The validity of the numerical predictions provided by the ABAQUS (2016) and PLATEBUCKLING (2015) programs is initially verified in this section through comparison of the critical buckling stresses for plates with different aspect and slenderness ratios as well as support condi- tions. The discrepancies between the criticalbuckling-stress predictions of the ABAQUS (2016) and PLATE-BUCKLING (2015) programs are tabulated in Table 3 . In the table, the results for 40 plate models with aspect ratios ranging between 0.5 and 2.5 are presented.

From Table 3, it is evident that the agreement between the numerical predictions of the ABAQUS (2016) and PLATE-BUCKLING (2015) programs is satisfactory. This verifies the accuracy of the present finite element modeling and analysis.

\section{Effect of Plate Aspect Ratio}

The effect of plate aspect ratio $(a / b)$ on buckling capacity is investigated for plates with different support conditions and the results are il-

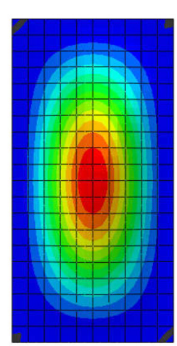

$a / b=0.5$

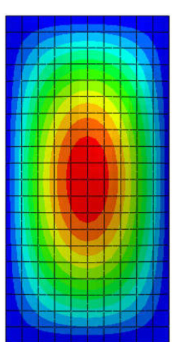

$a / b=0.5$

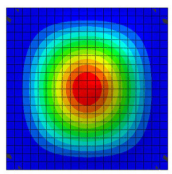

$a / b=1.0$

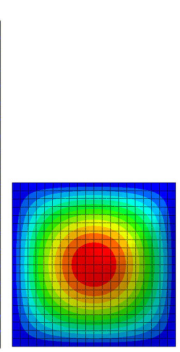

$a / b=1.0$

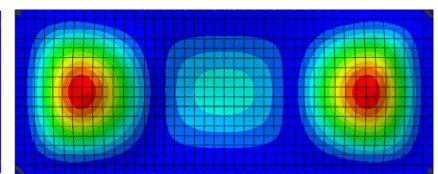

$a / b=2.0$

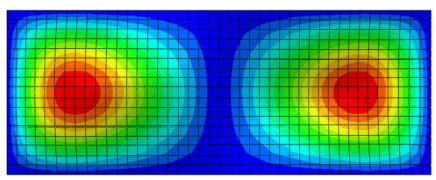

$a / b=2.0$ a)

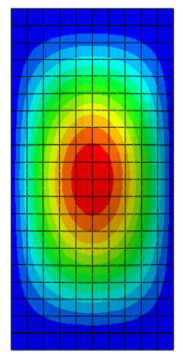

$a / b=0.5$

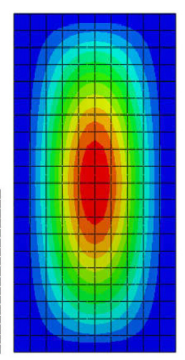

$a / b=0.5$

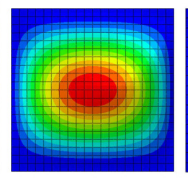

$a / b=1.0$

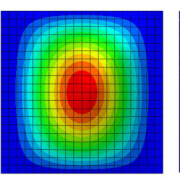

$a / b=1.0$ b)

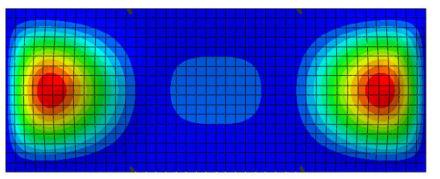

$a / b=2.0$

d)

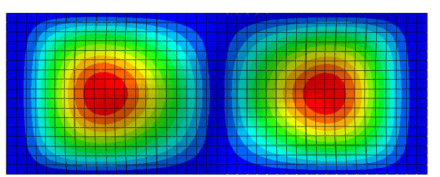

$a / b=2.0$

Fig. 3. The first buckling mode shapes for plates with different support conditions and aspect ratios, a) Support condition: CCCC, b) Support condition: CSCS, c) Support condition: SSSS, d) Support condition: SCSC 
Table 3. Comparison of numerical predictions of critical buckling stress for plates with different aspect and slenderness ratios as well as support conditions

\begin{tabular}{|c|c|c|c|c|c|}
\hline \multirow[t]{2}{*}{$\begin{array}{l}\text { Plate } \\
\text { model }\end{array}$} & \multirow[t]{2}{*}{$\begin{array}{l}\text { Aspect } \\
\text { ratio }\end{array}$} & \multicolumn{4}{|c|}{$\begin{array}{c}\text { Discrepancy }(\%) \text { between } \\
\text { ABAQUS and PLATE-BUCKLING } \\
\text { predictions }\end{array}$} \\
\hline & & $\mathrm{cccc}$ & cscs & SSSS & SCSC \\
\hline$P-1$ & \multirow{8}{*}{$\mathrm{a} / \mathrm{b}=0.5$} & 0.20 & 0.66 & 0.64 & 0.28 \\
\hline P-2 & & 0.88 & 0.64 & 0.75 & 0.35 \\
\hline P-3 & & 1.47 & 0.90 & 0.90 & 0.94 \\
\hline P-4 & & 2.09 & 0.76 & 0.65 & 0.34 \\
\hline P-5 & & 1.60 & 0.62 & 0.61 & 0.76 \\
\hline P-6 & & 1.52 & 0.92 & 0.55 & 0.94 \\
\hline P-7 & & 1.09 & 0.65 & 0.49 & 0.49 \\
\hline P-8 & & 2.34 & 0.64 & 0.45 & 0.34 \\
\hline P-9 & \multirow{8}{*}{$a / b=1.0$} & 1.01 & 1.30 & 1.26 & 1.84 \\
\hline$P-10$ & & 0.53 & 1.58 & 6.14 & 3.27 \\
\hline $\mathrm{P}-11$ & & 0.08 & 2.37 & 5.06 & 3.41 \\
\hline $\mathrm{P}-12$ & & 0.11 & 4.09 & 5.48 & 4.90 \\
\hline $\mathrm{P}-13$ & & 0.10 & 6.95 & 8.57 & 7.76 \\
\hline $\mathrm{P}-14$ & & 0.05 & 9.66 & 6.49 & 6.79 \\
\hline $\mathrm{P}-15$ & & 0.30 & 6.51 & 4.72 & 3.15 \\
\hline$P-16$ & & 0.37 & 8.85 & 10.18 & 6.59 \\
\hline$P-17$ & \multirow{8}{*}{$\mathrm{a} / \mathrm{b}=1.5$} & 1.70 & 2.44 & 1.63 & 4.83 \\
\hline $\mathrm{P}-18$ & & 1.17 & 2.73 & 1.6 & 3.68 \\
\hline P-19 & & 4.28 & 6.27 & 2.9 & 10.35 \\
\hline $\mathrm{P}-20$ & & 2.07 & 6.54 & 6.87 & 5.17 \\
\hline $\mathrm{P}-21$ & & 4.85 & 3.61 & 9.25 & 3.10 \\
\hline $\mathrm{P}-22$ & & 5.04 & 10.3 & 7.32 & 5.89 \\
\hline $\mathrm{P}-23$ & & 4.03 & 10.2 & 4.89 & 5.43 \\
\hline P-24 & & 3.05 & 4.44 & 4.62 & 5.05 \\
\hline P-25 & \multirow{8}{*}{$\mathrm{a} / \mathrm{b}=2.0$} & 1.37 & 1.52 & 1.87 & 2.34 \\
\hline P-26 & & 3.51 & 1.91 & 3.41 & 4.39 \\
\hline $\mathrm{P}-27$ & & 0.33 & 6.96 & 2.12 & 2.15 \\
\hline P-28 & & 3.61 & 5.62 & 1.41 & 3.27 \\
\hline P-29 & & 3.23 & 4.46 & 2.22 & 2.24 \\
\hline$P-30$ & & 3.21 & 8.01 & 1.17 & 9.26 \\
\hline P-31 & & 3.19 & 4.40 & 1.39 & 9.09 \\
\hline $\mathrm{P}-32$ & & 1.14 & 5.09 & 9.65 & 5.10 \\
\hline$P-33$ & \multirow{8}{*}{$\mathrm{a} / \mathrm{b}=2.5$} & 0.53 & 0.38 & 1.05 & 0.77 \\
\hline P-34 & & 3.78 & 0.94 & 1.89 & 1.39 \\
\hline P-35 & & 0.77 & 1.37 & 3.42 & 2.39 \\
\hline P-36 & & 1.26 & 9.98 & 1.69 & 6.64 \\
\hline$P-37$ & & 1.76 & 2.77 & 6.41 & 2.55 \\
\hline$P-38$ & & 0.34 & 2.69 & 14.18 & 0.33 \\
\hline P-39 & & 2.03 & 1.48 & 7.36 & 3.04 \\
\hline$P-40$ & & 0.45 & 0.33 & 8.09 & 1.74 \\
\hline
\end{tabular}

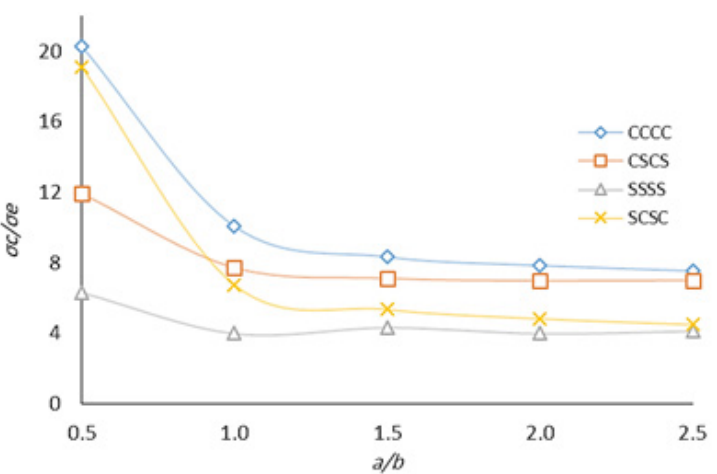

Fig. 4. Plot of $\sigma_{c r} / \sigma_{e}$ vs. $a / b$

lustrated in Fig. 4. In this figure, $\sigma_{c r} / \sigma_{e}$ is plotted against $a / b$, where $\sigma_{c r}$ is the critical stress determined numerically using ABAQUS (2016) software and $\sigma_{e}$ is the Euler stress predicted by the PLATE-BUCKLING (2015) program.

From Fig. 4, it is found that increasing of the $a / b$ ratio from 0.5 to 1.0 results in considerable reduction of the $\sigma_{c r} / \sigma_{e}$ ratio, while increasing of the aspect ratio beyond unity does not seem to have a remarkable effect on the buckling strength of the plate. It is evident that plates with SSSS and CCCC support conditions possess the lowest and the highest buckling strengths, respectively.

These results, also, indicate the effectiveness of fixity of the loading edges, i.e. 2 (BD) and 4 (AC) shown in Fig. 1 and Table 1, on improving the buckling strength of plates as $a / b$ ratio gets smaller than unity, while by increasing of the $a / b$ ratio beyond unity this effect diminishes. Accordingly, for $a / b<$ 1.0 , the plate with SCSC support conditions possesses a relatively higher buckling capacity compared to the one with CSCS support conditions, while this trend is reversed for $a / b>1.0$. It is seen that the buckling capacities of plates with $\mathrm{CCCC}$ and CSCS as well as SCSC and SSSS support conditions get closer as the $a / b$ ratio increases.

Based on the numerical results obtained from ABAQUS (2016), the ultimate strength of the slender plates is much higher than their buckling capacity. This is attributed to the considerable post-buckling reserve of slender plates.

\section{Performance Assessment Using Plate “Design Ratio"}

According to EN 1993-1-5 (2006), the interaction between a plate type and local buckling behavior is determined by Design Ratio. When the value of this parameter, i.e. Design Ratio, ap- 

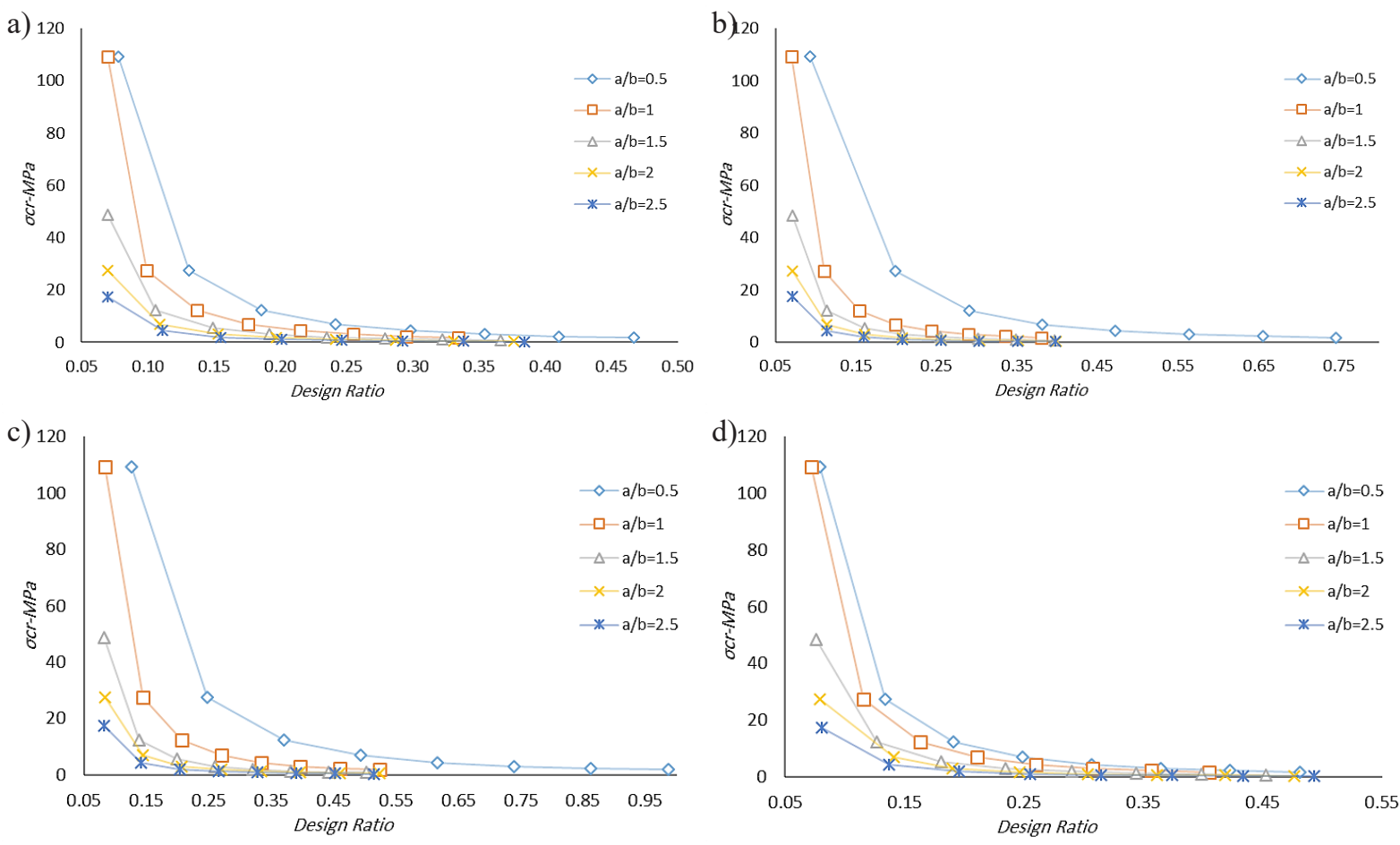

Fig. 5. Plots of plate critical stress versus Design Ratio, a) Support condition: CCCC, b) Support condition: CSCS, c) Support condition: SSSS, d) Support condition: SCSC

proaches unity, it indicates that the plate design is economical. Design Ratio can be considered as an effective parameter for optimal design of plates. On this basis, this parameter is used in order to evaluate the buckling behavior of the plates under study. In this research, the Design Ratio was determined using the PLATE-BUCKLING (2015) program for all models, which is calculated using Eq. (1). In this equation, the partial safety factor $\left(\gamma_{\mathrm{M} 1}\right)$ is taken as 1.1.

$$
\text { Design Ratio }=\left(\frac{\sigma_{x}}{\left(\rho_{c} \times f_{y}\right) / \gamma_{M 1}}\right)
$$

The plots of $\sigma_{c r}$ versus Design Ratio for plates with different aspect ratios as well as support conditions are shown in Fig. 5.

Consistent with all support conditions shown in Figs. 5(a) through 5(d), the highest buckling capacities are found to be in Design Ratios ranging between 0.05 and 0.15 . Increasing of value of the Design Ratio beyond the aforementioned range results in significant degradation of the buckling strength and also decreasing of the effect of $a / b$ ratio on buckling capacity of the plate. From Fig. 5 , it is also found that the buckling capacity of plates with lower $a / b$ ratios, especially $a / b \leq 1.0$, is considerably high. Furthermore, comparison of the results depicted in Figs. 5(a) and 5(c) demon- strates that plates with CCCC support condition are less economical compared to those with SSSS support condition.

\section{Effect of Plate Thickness-to-Width Ratio}

Fig. 6 shows the relationship between the Design Ratio and thickness-to-width $(t / b)$ ratio for plates with different aspect ratios and support conditions.

From Fig. 6, it is evident that increasing of $t / b$ ratio results in decreasing of value of the Design Ratio in all cases. This indicates that increasing of plate thickness, i.e. use of more material, and/ or decreasing of length of the loaded edges $(b)$, i.e. increasing of plate $a / b$ ratio, will adversely affect the economical and optimal design of plates. In addition, comparison of the results shown in Figs. 6(a) and 6(c), time and again, confirms that plates with SSSS support condition can be more economical relative to those with clamped supports on all four edges.

The results of this case study also demonstrate that the optimal $t / b$ ratio lies between 0.002 and 0.004 . Moreover, evaluation of the plots shown in Figs. 6(a) through 6(d), expect for those for $a / b$ $=0.5$, indicates that the effects of different aspect ratios on determination of the corresponding Design Ratio and $t / b$ ratio are quite minimal. This is 

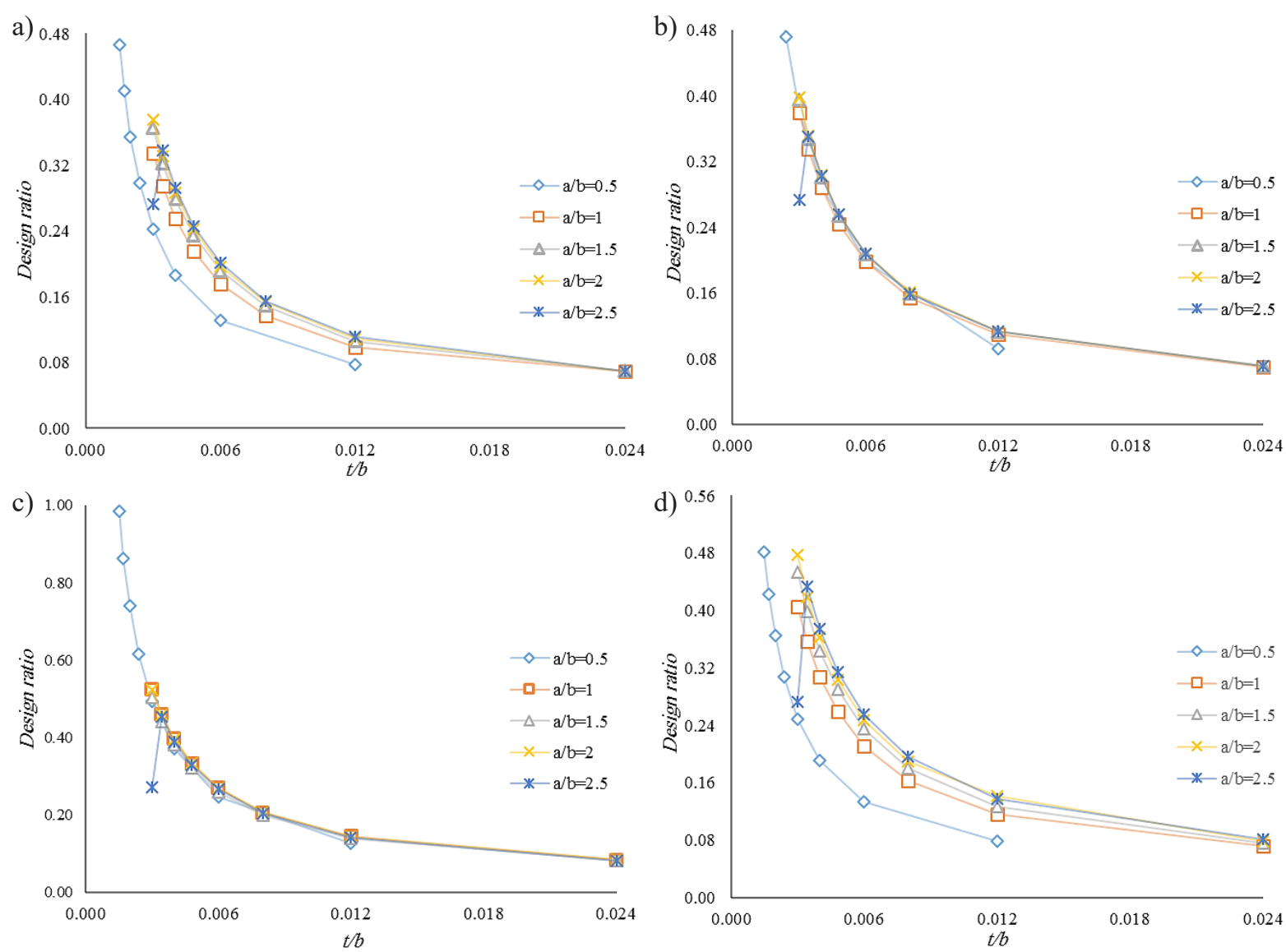

Fig. 6. Plots of plate Design Ratio versus $t / b$ ratio, a) Support condition: CCCC, b) Support condition: CSCS, c) Support condition: SSSS, d) Support condition: SCSC

attributed to the fact that the curves corresponding to $a / b$ ratios ranging from 1.0 to 2.5 coincide in case of each support condition.

\section{Effect of Plate Slenderness Ratio}

In this case study, the effect of plate slenderness ratio $(\beta)$ is investigated by considering plates with slenderness ratios ranging from 5.4 to 86.7 and different support conditions, i.e. CCCC, CSCS, SSSS, and SCSC. Herein, $\beta$ is determined by using Eq. (2). The plots of Design Ratio versus slenderness ratio are illustrated in Fig. 7.

$$
\beta=\left(\frac{b}{t}\right) \times\left(\sqrt{\frac{\sigma_{y}}{E}}\right)
$$

As it is seen in Fig. 7, increasing of $\beta$ results in increasing of value of the Design Ratio in all cases and Design Ratio indeed tends to approach unity. It is quite evident that plates with SSSS and CCCC support conditions possess the highest and the lowest values of Dsign Ratio. Furthermore, by increasing of value of the $a / b$ ratio from 0.5 to
2.5, the plots of SCSC and CSCS support conditions tend to approach the plots of SSSS and CCCC support conditions, respectively. This finding is quite consistent with the one discussed in section 4.2.

\section{CONCLUSION}

The comprehensive and systematic study of buckling stability of thin plates is of great importance in effective design and detailing of such thin-walled elements with widespread engineering applications. In this paper, the buckling stability of rectangular plates with four types of support conditions, i.e. CCCC, SSSS, CSCS, and SCSC, as well as five different aspect ratios, i.e. $a / b=0.5,1.0,1.5,2.0$, and 2.5 , under uniaxial compression was further investigated through numerical simulation. ABAQUS (2016) and PLATE-BUCKLING (2015) programs were used for modeling and analysis of the considered plate models. The numerical predictions of the two aforementioned programs were compared for 

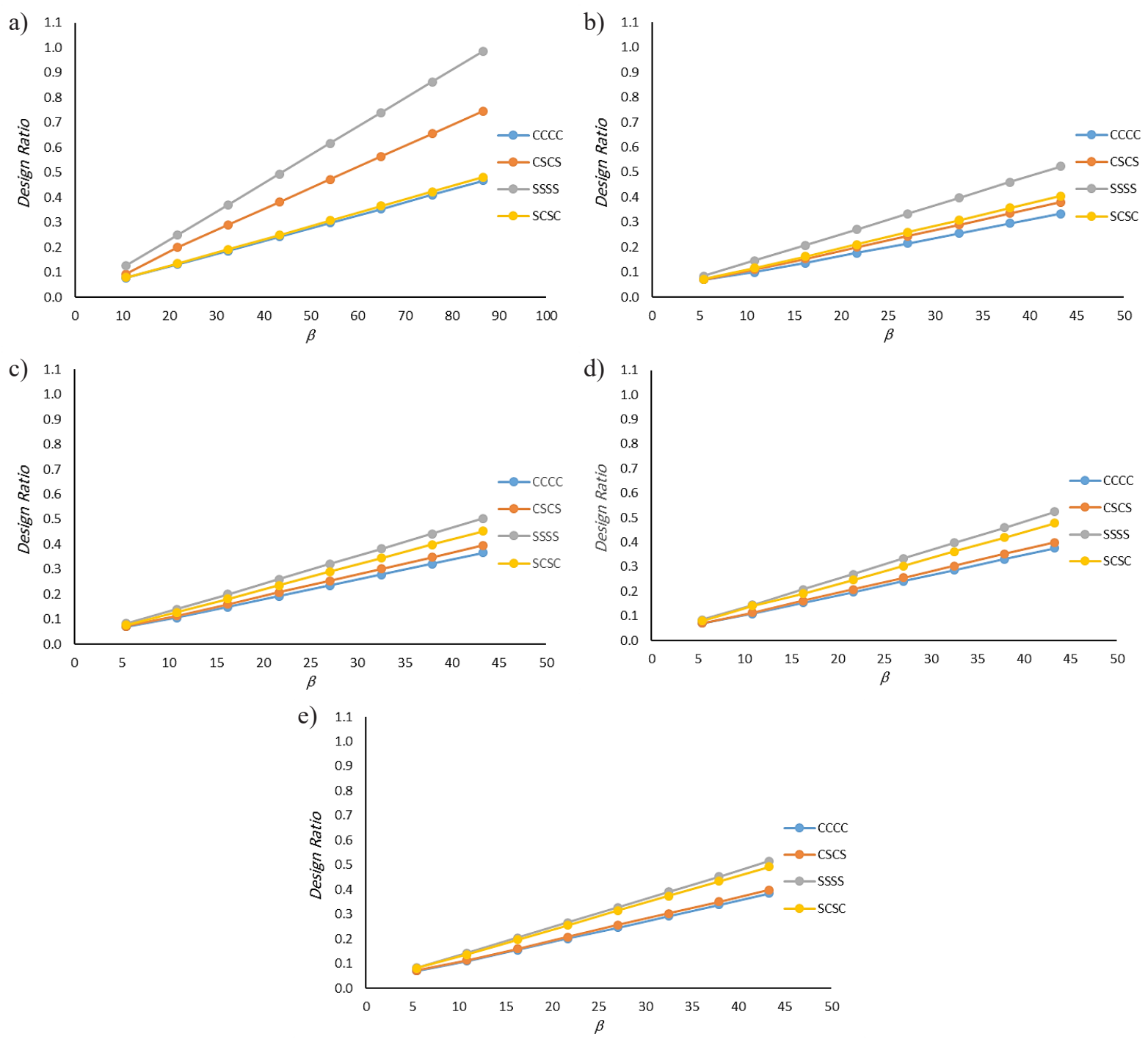

Fig. 7. Plots of plate Design Ratio vs. slenderness ratio, a) $a / b=0.5, b) a / b=1.0, c) a / b=1.5, d) a / b=2.0, e$ ) $a / b=2.5$

verification purposes. The major findings of this research are summarized in the following:

- Fixity of the loading edges can be effective in improving the buckling strength of plates as the aspect ratio gets smaller than unity, while loading edges fixity does not seem to have a considerable effect on the buckling capacity in plates with aspect ratios larger than unity.

- The highest buckling capacities of plates were found to occur in Design Ratios ranging between 0.05 and 0.15 . Further increasing of value of the Design Ratio was shown to result in significant degradation of the buckling strength and decreasing of the effect of $a / b$ ratio on the buckling strength. Plates with CCCC support condition were shown to be less economical than those with simple supports on all four edges.
- It was shown that increasing of $t / b$ ratio results in decreasing of value of the Design Ratio. In other words, increasing of plate thickness (more material) and/or decreasing of length of the loaded edges (higher $a / b$ ratio), will adversely affect the economical and optimal design of plates.

- Increasing of $\beta$ results in increasing of value of the Design Ratio. Plates with SSSS and CCCC support conditions possess the highest and the lowest values of Dsign Ratio.

\section{NOMENCLATURE}

$\begin{array}{cc}a, b & \text { panel dimensions } \\ A_{p} & \text { plate cross-sectional area }(b \times t) \\ E & \text { modulus of elasticity }\end{array}$




$\begin{array}{cc}k & \text { buckling coefficient } \\ t & \text { plate thickness } \\ u, v, w & \text { displacement components } \\ x & \text { distance across the length of plate } \\ y & \text { distance across the width of plate } \\ \alpha(=a / b) & \text { length-to-width ratio of the plate } \\ \beta & \text { plate slenderness ratio } \\ \gamma_{x y}, \gamma_{x z}, \gamma_{y z} & \text { shear strain components } \\ \varepsilon_{x}, \varepsilon_{y}, \varepsilon_{z} & \text { normal strain components } \\ \bar{\lambda}_{p} & \text { plate slenderness } \\ v & \text { Poisson's ratio } \\ \sigma_{c r} & \text { critical buckling stress } \\ \sigma_{e} & \text { Euler critical stress } \\ \sigma_{x}, \sigma_{y}, \sigma_{z} & \text { normal stresses } \\ \sigma_{y} & \text { yield stress } \\ \tau_{x y}, \tau_{x z}, \tau_{y z} & \text { shear stresses } \\ \gamma_{M 1} & \text { partial safety factor } \\ \rho_{c} & \text { reduction factor }\end{array}$

\section{REFERENCES}

1. ABAQUS (2016). ABAQUS/Standard Theory Manual. K. Hibbitt, Sorenson, Inc./HKS, Pawtucket, Rhode Island.

2. Bryan G.H. (1890). "On the stability of a plane plate under thrusts in its own plane, with applications to the buckling of the sides of a ship", Proceedings of the London Mathematical Society, s122(1), 54-67, DOI: 10.1112/plms/s1-22.1.54.

3. Cox H.L. (1933). The Buckling of Thin Plates in Compression. British Aeronautical Research Committee, Reports and Memoranda, No. 1554.

4. Cox H.L. (1963). The Buckling of Plates and Shells. Macmillan, New York.

5. Dinnik A.N. (1911). "On stability of a compressed circular plate”, Proceedings of the Kiev Polytechnic Institute, Kiev. (In Russian)

6. EN 1993-1-5 (2006). Euro code 3: Design of Steel Structures-Part 1-5: Plated Structural Elements. European Committee for Standardization, Brussels.

7. Gerard G. and Becker H. (1957). Handbook of Structural Stability: Part1 - Buckling of Flat Plates. NACA TN 3781.
8. Kilardj M., Ikhenazen G., Messager T., and Kanit T. (2016). "Linear and nonlinear buckling analysis of a locally stretched plate", Journal of Mechanical Science and Technology, 30(8), 3607-3613.

9. Latifi M., Farhatnia F., and Kadkhodaei M. (2013). "Buckling analysis of rectangular functionally graded plates under various edge conditions using Fourier series expansion", European Journal of Mechanics - A/Solids, 41(September-October), 16-27.

10. Mijušković O., Ćorić B., and Šćepanović B. (2014). "Exact stress functions implementation in stability analysis of plates with different boundary conditions under uniaxial and biaxial compression", Thin-Walled Structures, 80(July), 192-206, DOI: 10.1016/j.tws.2014.03.006.

11. Najafizadeh M.M., Mahdavian M., and Khazaeinejad P. (2010). "Superposition buckling analysis of rectangular plates composed of functionally graded materials subjected to non-uniform distributed in-plane loading", Proceedings of the Institution of Mechanical Engineers, Part C: Journal of Mechanical Engineering Science, 224(11), 2299-2307, DOI: 10.1243/09544062JMES2134.

12. Navier C.L.M.H. (1823). Bulletin des Sciences de la Societe Philomathique de Paris. Paris.

13. PLATE-BUCKLING (2015). Dlubal Software: Plate Buckling Analysis for Stiffened and Unstiffened Plates According to EN 1993-1-5 and DIN 18800-3.

14. Rammerstorfer F.G. (2018). "Buckling of elastic structures under tensile loads", Acta Mechanica, 229(2), 881-900.

15. Rouegar J. and Sharifpoor R.A. (2017). "Finite Element Formulations for Buckling Analysis of Isotropic and Orthotropic Plates using Two-Variable Refined Plate Theory", Iranian Journal of Science and Technology, Transactions of Mechanical Engineering, 41(3), 177-187.

16. Southwell R.V. and Scan S. (1924). "On the stability under shearing forces of a flat elastic strip", Proceedings of the Royal Society of London, A105(733), 582-607, DOI: 10.1098/rspa.1924.0040.

17. Timoshenko S.P. and Gere J.M. (1961). Theory of Elastic Stability. ${ }^{\text {nd }}$ Ed., McGraw-Hill, New York.

18. Ventsel E. and Krauthammer T. (2001). Thin Plates and Shells; Theory, Analysis, and Applications. Marcel Dekker, Inc., New York. 